\title{
ВОССТАНОВЛЕНИЕ СВОЙСТВ МЕТАЛЛА ЛОПАСТЕЙ ЦИРКУЛЯЦИОННЫХ НАСОСОВ МЕТОДОМ ПОВЕРХНОСТНОЙ УЛЬТРАЗВУКОВОЙ УДАРНОЙ ОБРАБОТКИ
}

\author{
(C) 2017 В. П. Поваров ${ }^{1}$, О. В. Уразов ${ }^{1}$, М. Б. Бакиров ${ }^{2}$, С. С. Пахомов² \\ ${ }^{\prime}$ Филиал АО «Кониерн Росэнергоатом» «Нововоронежская атомная станция», НВАЭС, \\ промышленная зона Южная, 1, 1396071 Воронежская обл., г. Нововоронеж, Россия \\ ${ }^{2} О О О$ «Научно-сертификаиионный учебный центр материаловедения и ресурса компонентов \\ ядерной техники« (НСУЦ «ЦМиР»), ул. Жуковского, д. 1, 140180 Московская обл., г. Жуковский, Россия \\ e-mail:PovarovVP@nvnpp1.rosenergoatom.ru,UrazovOV@nvnpp1.rosenergoatom.ru
}

Поступила в редакцию 10.04.2017 г.

\begin{abstract}
Аннотация. Данная работа посвящена разработке и практическому внедрению восстановительной технологии упрочняющей ультразвуковой обработки металла лопастей рабочих колес насосов циркуляционных блочной насосной станции Нововоронежской АЭС-2. Динамическая поверхностная обработка проводилась с целью компенсации технологических дефектов металла лопастей. Было показано, что ударное упругопластическое деформирование оказывает комплексное компенсирующее воздействие на металл лопастей в исходном состоянии поставки и создает поверхностный упрочняющий слой с повышенными прочностными характеристиками глубиной до 1.5 мм. Поверхностный наклеп повышает циклическую прочность, выгодно перераспределяет остаточные технологические и ремонтные напряжения, а также «залечивает» мелкие поверхностные трещины, улучшая качество поверхности. По разработанной технологии была проведена обработка 32 лопастей рабочих колес циркуляционных насосов 10РAC01AP001, 10РAC02АР001, 10РАС03АР001, 10РАС04АР001. Проведенные 100-часовые натурные испытания насосов показали высокую эффективность разработанной технологии и позволяют рекомендовать ее использование как на стадии производства лопастей, так и в процессе эксплуатации насосов с целью продления их срока службы.
\end{abstract}

Ключевые слова: пластическое деформирование, поверхностный дефект, остаточные сварные напряжения, ультразвуковая ударная обработка, циркуляционный насос.

\section{ВВЕДЕНИЕ}

При проведении индивидуальных испытаний циркуляционных насосов энергоблока № 1 Нововоронежской АЭС-2 были обнаружены поверхностные трещины в основном металле лопастей рабочего колеса циркуляционных насосов.

В ходе расследования причин образования трещин в металле лопастей, проведенного различными материаловедческими организациями, в том числе и Центром материаловедения и ресурса, были получены следующие результаты.

Согласно сертификатным данным лопасти изготовлены по ГОСТ 977 из стали 12Х18Н9ТЛ. Капиллярная дефектоскопия по ГОСТ 18442 [1-2] выявила наличие микро- и макротрещин различной протяженности на выходном участке лопасти, предоставленной на экспертизу.
Микроструктурный анализ [3-5] показал, что металл лопасти имеет крупнозернистую аустенитную структуру с номером зерна больше -3 по ГОСТ 5639-82, и что он поражен литейными дефектами (порами и неметаллическими включениями), расположенными как по границам, так и внутри зерен. Эти дефекты имеют как эндогенную, так и экзогенную природу. Зачастую неметаллические включения и поры объединяются в микротрещины. Расположение скоплений пор случайное и не привязано к расположению осей дендритов.

Такая микроструктура приводит к снижению коррозионной стойкости стали и ухудшению эксплуатационных характеристик изделия, что подтвердили испытания на стойкость к межкристаллитной коррозии. Образцы не выдержали испыта- 
ний, было зафиксировано распространение трещины на глубину до 1.5 мм.

В сложившейся ситуации с целью приведения служебных свойств металла лопастей к приемлемому уровню возникла необходимость разработки ремонтной восстановительной технологии, включающей выборку недопустимых дефектов и проведение сварочных процедур с последующей ультразвуковой ударной обработкой (УУО) всей поверхности лопасти.

Проведение УУО позволило улучшить физико-механические и усталостные характеристики поверхностного слоя изделия, а также «залечить» поверхностные трещины в основном металле лопастей рабочего колеса циркуляционных насосов.

\section{МЕТОДИКА ЭКСПЕРМЕНТА}

Ультразвуковая ударная обработка - один из наиболее эффективных методов, реально позволяющих повысить качество, надежность и ресурс металла конструкций. Для такой обработки не требуется жесткая фиксация рабочего инструмента и, таким образом, она наиболее подходит для изделий со сложной формой поверхности, такой как лопасть насоса.

Данный метод относится к методам холодной обработки металлов. В [6] установлено, что наилучшим образом обработка выполняется вибро- инструментом с источником механической энергии в виде резонатора упругих колебаний ультразвуковой частоты, который передает ударные импульсы посредством деформирующих элементов игл-бойков или инденторов.

В результате пластической деформации поверхностного слоя увеличивается твердость металла, образуются остаточные сжимающие напряжения, снижается шероховатость, что благоприятно влияет на ресурс деталей.

На рис. 1 показаны зоны физического воздействия УУО на металл в поперечном разрезе поверхностного слоя.

В зоне пластической деформации увеличивается циклическая долговечность и коррозионно-усталостная прочность, происходит компенсация деформаций. В зонах импульсной и ультразвуковой релаксации снижаются остаточные сварочные напряжения и деформации (в первом случае до 70 \%, во втором - до 50 \% исходного состояния).

Таким образом, на глубине 0.02-0.10 мм создается тонкий поверхностный слой металла, повышающий износостойкость и коррозионную стойкость изделия. Как показывают исследования [5], под воздействием ударных импульсов на ультразвуковой частоте в поверхностном слое возникают напряжения, достаточные для преодоления дислокациями потенциальных барьеров и более раннего начала

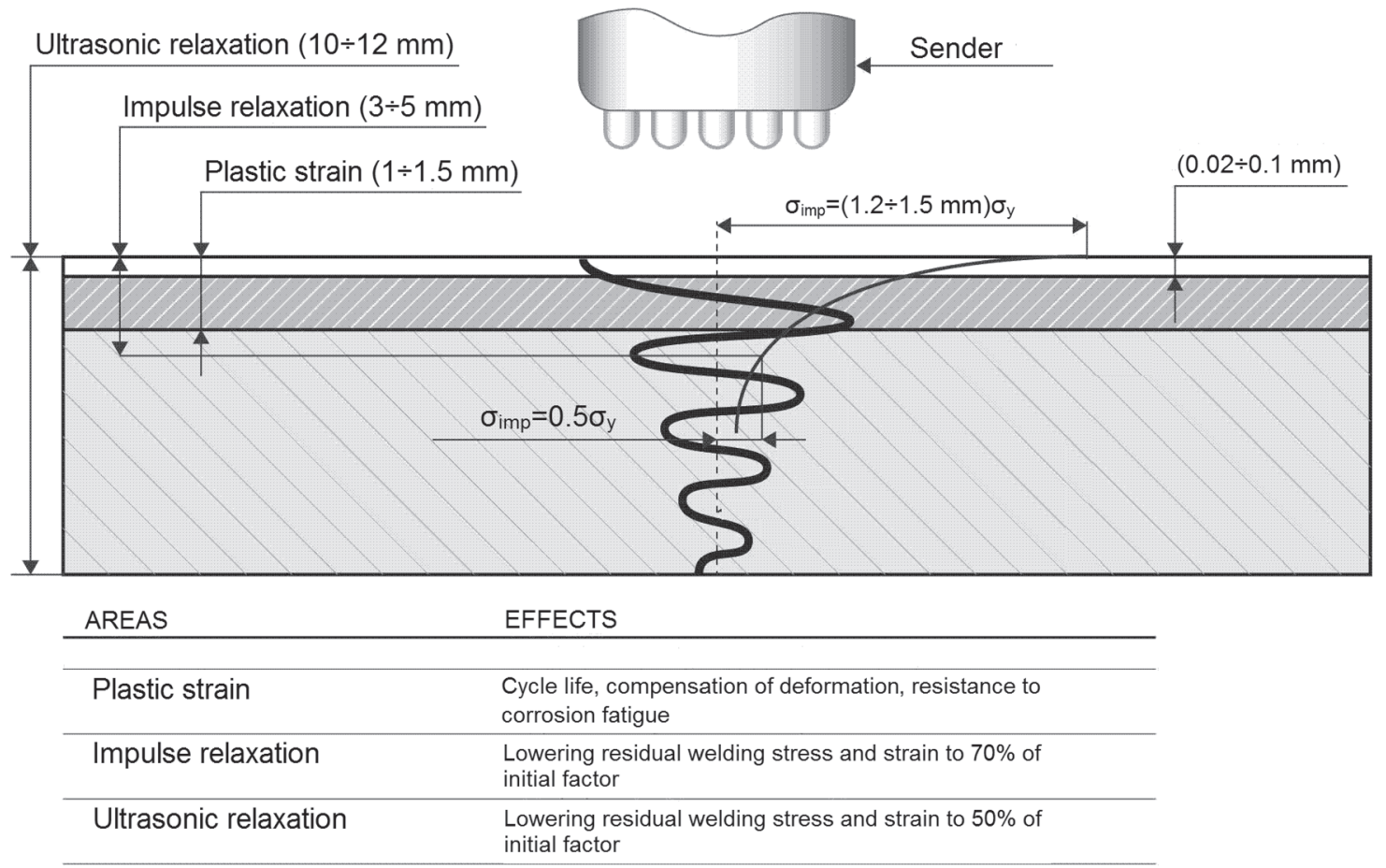

Рис. 1. Физические зоны влияния ультразвуковой ударной обработки

[Fig. 1. Ultrasonic impact treatment affected areas] 
пластического течения. Воздействие ультразвука также активизирует движение дислокаций, задержанных на препятствиях (границы зерен, примесные атомы, вторая фаза и т.д.), и способствует зарождению дислокаций внутри существующих источников Франка-Рида, таким образом, облегчая процесс пластической деформации.

Ультразвуковое воздействие формирует в поверхностном слое сжимающие остаточные напряжения, в результате чего этот слой упрочняется, а шероховатость поверхности уменьшается. Глубина упрочненного слоя для различных видов сплавов и сталей может достигать нескольких миллиметров.

Метод поверхностной УУО позволяет получать регулярный микрорельеф с управляемыми геометрическими параметрами (формой, высотой, размерами его фрагментов). Кроме того, данная обработка способствует «лечению» мелких микротрещин, полученных на предшествующих этапах производственного цикла. При этом происходит формирование и равномерное распределение остаточных напряжений сжатия в поверхностном слое, которые в свою очередь снижают скорость распространения усталостных трещин.

Для определения влияния ультразвукового упрочнения на поверхностный слой металла, оценки упрочняющего эффекта и отработки оптимальных (с точки зрения компенсации дефектности обрабатываемого металла) режимов ультразвукового воздействия были проведены испытания на тест-образцах.

Для исследований в лабораторию механических испытаний Центра материаловедения и ресурса компонентов ядерной техники (НСУЦ «ЦМиР») была передана вырезка металла размерами $180 \times 75 \times 40$ мм из лопасти рабочего колеса насоса блочной насосной станции Нововоронеж- ской АЭС-2, изготовленной из стали 12 Х18Н9ТЛ, ГОСТ 977-88.

Часть рабочей поверхности вырезки из лопасти площадью $50 \times 75$ мм была подвергнута ультразвуковой ударной обработке с помощью ультразвукового прибора.

Из металла вырезки были изготовлены образцы на одноосное растяжение по типу ІІІ в соответствии с ГОСТ 1497-84 и для испытаний на твердость.

Измерение микротвердости металла вырезки проводили в соответствии с ГОСТ 2999-75 [7] на твердомере Zwick ZHV10.

Испытания на растяжение образцов, изготовленных из металла вырезки, проводили на машине Zwick Z100 с непрерывной регистрацией показаний датчиков силы и перемещения в соответствии с ГОСТ 1497-84 [8]. Температура испытаний $20{ }^{\circ} \mathrm{C}$.

Также исследовались образцы стали 12Х18Н9ТЛ. Образец представляет собой пластину толщиной 10 мм с инициирующим вырезом 4 мм и выращенной трещиной длиной 27 мм.

Обработка образца осуществлялась с помощью ультразвукового прибора. К торцу магнитострикционного преобразователя крепилось 5 инденторов с радиусом закругления 3 мм. Диапазон частоты ультразвуковых колебаний составлял 20-27 кГц. Усилие прижима деформирующих элементов к поверхности $20-50 \mathrm{H}$.

Обработка проводилась по поверхности образца вдоль трещины с двух сторон, с произвольной скоростью перемещения.

\section{ЭКСПЕРИМЕНТАЛЬНЫЕ ИССЛЕДОВАНИЯ}

Были опробованы два способа обработки поверхности (рис. 2). При первом способе проводилась равномерная обработка стороны 1 в окрест-

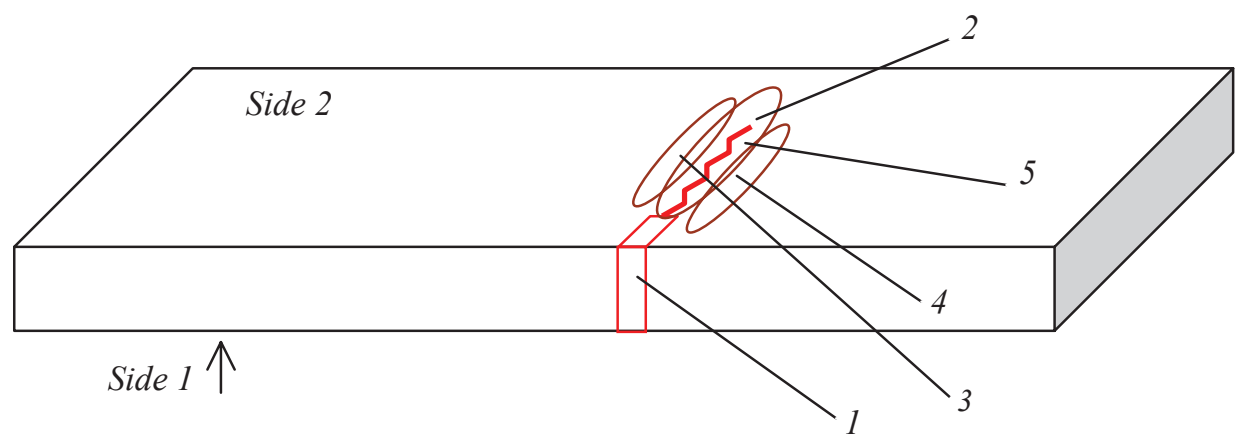

Рис. 2. Схема обработки образца из стали 12 Х18Н9ТЛ с трещиной: 1 - инициирующий надрез; 2 - усталостная трещина; 3-5 - последовательность обработки металла с трещиной

[Fig. 2. Conditioning outline for a cracked steel sample 12X18H9TL: 1 - starter notch; 2 - fatigue crack; 3-5 - cracked metal processing sequence] 
ности трещины. При втором - «оптимизированная» процедура обработки стороны 2, состоящая из первичной обработки металла вдоль краев трещины для их схлопывания (зоны 3 и 4) с последующей обработкой непосредственно трещины сверху (зона 5).

\section{Численное моделирование}

Для оптимизации режимов и технологии процесса упрочнения было проведено численное моделирование процесса обработки образца, содержащего искусственный трещиноподобный дефект известной формы и размеров (трещина шириной раскрытия 0.04 мм, глубиной 1.5 мм). Разработанная конечно-элементная модель позволяет произвести расчет процесса упругопластической деформации материала при различных режимах нагружения. При разработке расчетной модели были приняты следующие допущения:

- индентор представляется абсолютно жестким;

- трение между идентором и обрабатываемой поверхностью отсутствует;

- деформированное состояние является плоским, т.е. задача решается в двумерной постановке.

Последнее допущение было введено из необходимости моделирования процесса обработки поверхности большого размера, так как трехмерная постановка приводит к существенному увеличению количества элементов и шагов нагружения.

Базовые параметры расчетной модели:

- материал обрабатываемого образца - сталь 12Х18Н9ТЛ;

- радиус индентора $R=3$ мм.

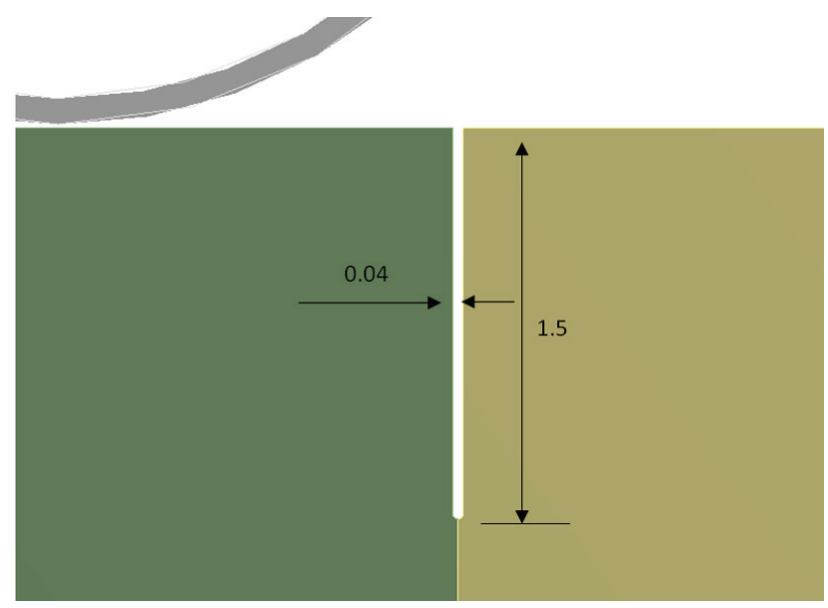

Принятый в расчете искусственный трещиноподобный дефект и модель нагружения представлены на рис. 3. Обработка производилась со скоростью $v=3$ мм/с с одновременным контролем глубины вдавливания $U$, мм. Решалась задача плоского деформированного состояния (ПДС) квазистатического вдавливания на постоянную эквивалентную глубину. Эквивалентная глубина вдавливания - глубина, найденная путем сравнения распределения твердости по глубине после обработки образца лопасти насоса методом УУО с расчетными значениями, используемая в конечно-элементной модели $(U=0.02 \mathrm{MM})$.

\section{ОБСУЖДЕНИЕ РЕЗУЛЬТАТОВ}

Произведено две одинаковые серии измерений микротвердости по Виккерсу (с усилием 1.96 Н) в поперечном сечении образца начиная от кромки обработанной поверхности вглубь образца с шагом 100 мкм. Результаты измерений представлены на рис. 4.

Кривые микротвердости спадают от максимального значения на обработанной поверхности образца (примерно 270 HV) до 160-170 HV на глубине 0.9 мм и далее стабилизируются на глубине $1.5 \mathrm{MM}$.

Этапы упругопластической деформации, возникающей в результате обработки в соответствии с выбранной технологией, иллюстрирующие процесс упрочнения, а также смыкание берегов заложенного в модель трещиноподобного дефекта («залечивания»), представлены на рис. 5.

Сравнение полученных расчетных результатов (рис. 5) и результатов лабораторных исследований

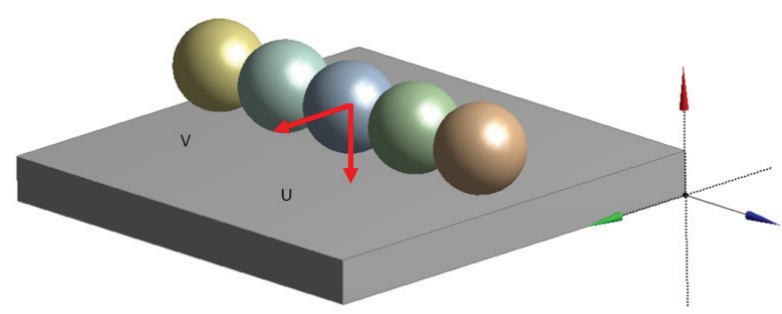

Рис. 3. Принятый в расчете искусственный трещиноподобный дефект и модель нагружения

[Fig. 3. Crack-like defect and fatigue model, taken into calculation] 
(рис. 6) показывает хорошее совпадение картин. Это позволяет сделать вывод об эффективности выбранной технологии для создания защитного наклепанного слоя и смыкания берегов трещиноподобных дефектов («залечивания») от ширины раскрытия 0.04 до 0.004 мм. Глубина, на которую распространяется эффект упрочнения (применительно к исследуемой стали), составляет около 1 мм.

Таким образом, проведенные расчетно-экспериментальные исследования позволяют сформулировать достоинства рассматриваемого метода. При использовании УУО:

- создается благоприятное поле сжимающих остаточных напряжений на глубину до 1.5мм;

- «залечиваются» поверхностные дефекты путем смыкания устья трещины у поверхности на глубину до 1 мм.
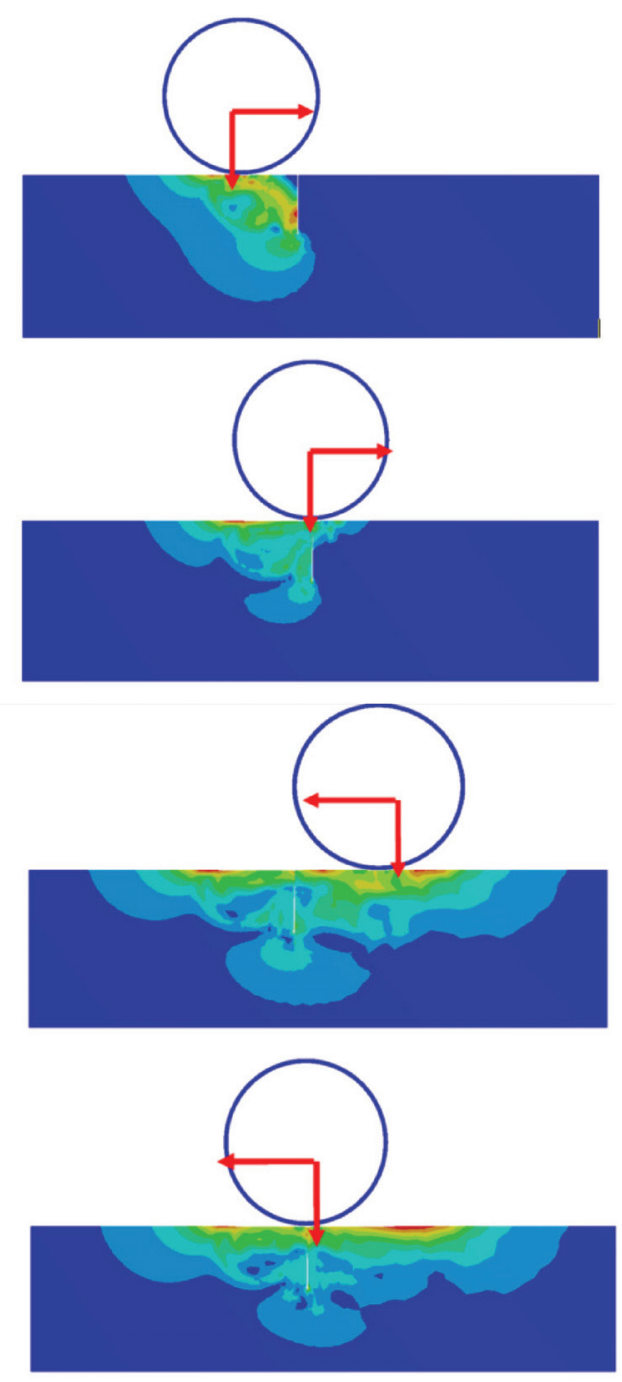

Step 3

Step 1

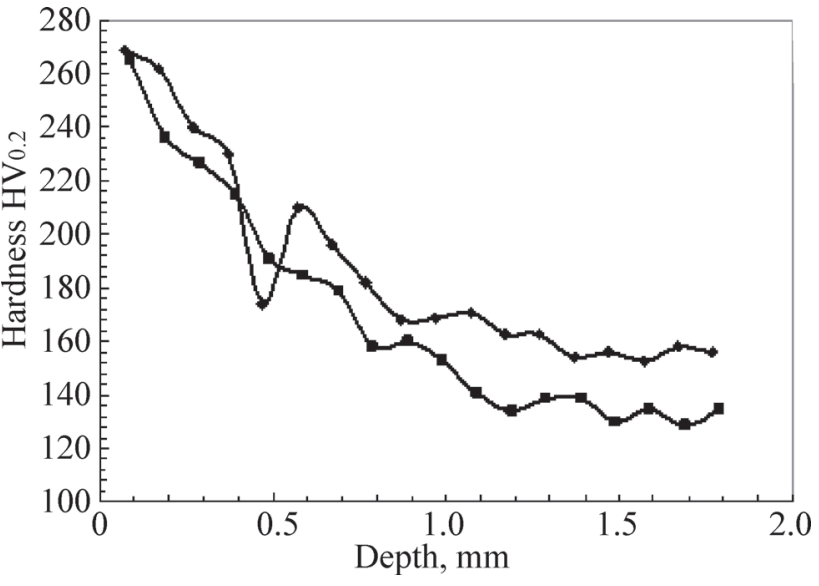

Рис. 4. Изменение микротвердости по Виккерсу в поперечном сечении образца. Номера кривых соответствуют номерам серий измерений

[Fig. 4. Vickers microhardness variation in sample crosscut. Curve numbers correspond with numbers of measurement runs]

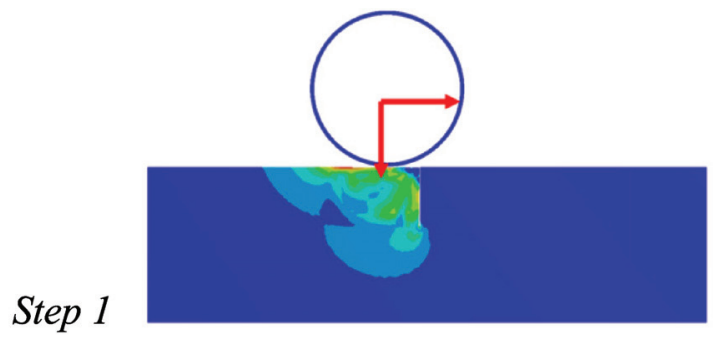

Step 2
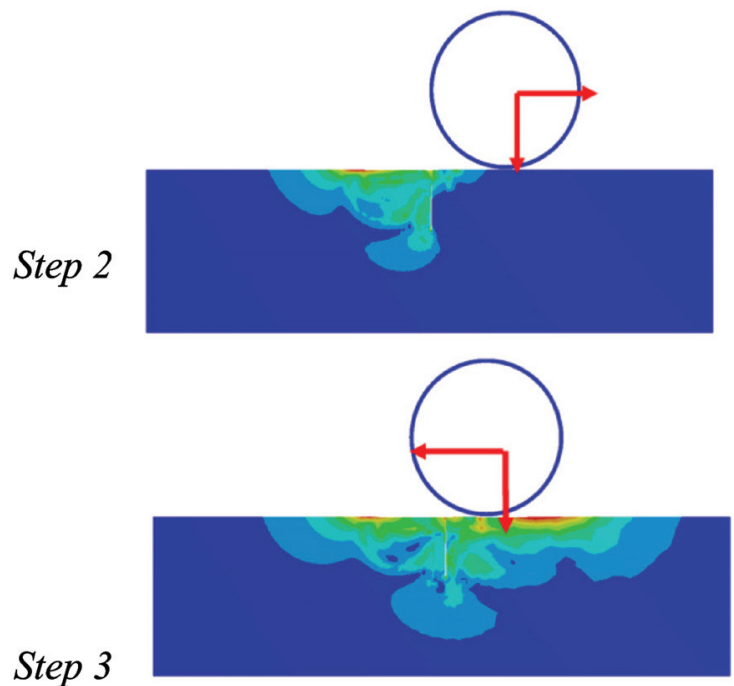

Step 4

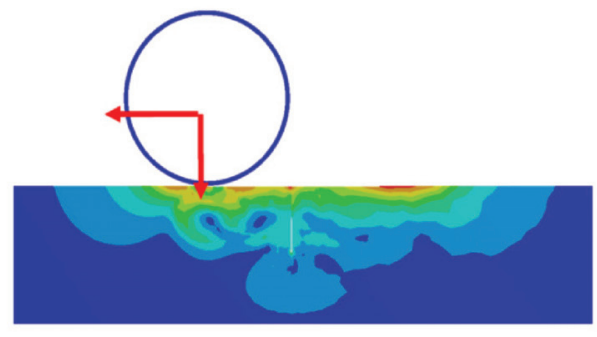

Рис. 5. Распределение упругопластической деформации поверхности в результате проведения ультразвуковой обработки

[Fig. 5. Elastoplastic strain distribution as a result of an ultrasonic conditioning] 


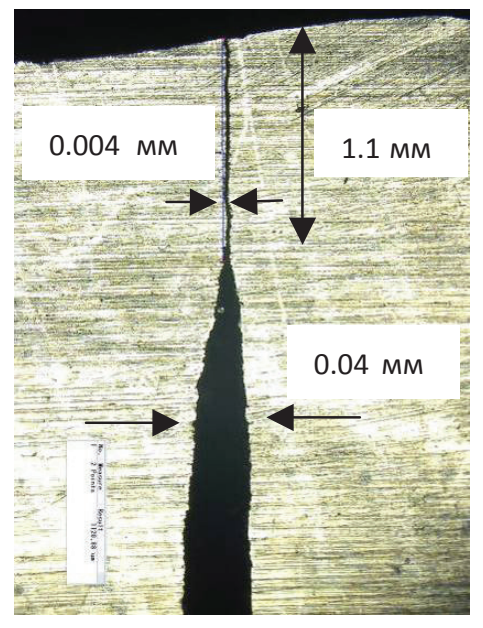

Рис. 6. Вид поперечного сечения образца стали 12Х18Н9ТЛ вблизи трещины после проведения упрочнения методом УУО. Увеличение $\times 100$

[Fig. 6. Cross-sectional view of the steel sample 12X18H9T near the crack after an ultrasonic impact treatment. Zoomed $\times 100]$

Проведенные исследования показали высокую эффективность процедуры упрочнения: до глубины 0.5 мм прочность образца возрастает на $30 \%$.

При этом, несмотря на высокую остаточную пластичность межкристаллитная прочность низкая. Слабые межзеренные связи неизбежно приводят к снижению трещиностойкости металла. Объем исследуемого металла, вырезанного из лопасти, не позволил изготовить образцы для испытаний на определение статической трещиностойкости. В связи с этим было принято решение изготовить из металла вырезки два образца на одноосное растяжение по ГОСТ 1497-84 [9].

Цель данных испытаний получить фактические прочностные свойства материала, оценить его поведение при необратимой пластической деформации, сравнить влияние ультразвукового упрочнения на свойства материала при упругопластической одноосной деформации.
Один образец испытывался на одноосное растяжение согласно ГОСТ 1497-84 в исходном состоянии. Второй образец предварительно обрабатывался следующим образом: вся рабочая поверхность упрочнялась тем же прибором, которым проводилась обработка лопасти. Для этого была разработана технология, которая позволяет провести равномерный наклеп всей рабочей поверхности образца. После ультразвуковой обработки образец также испытывался на растяжение согласно ГОСТ 1497-84.

Для большинства конструкционных сталей на стадии пластического деформирования в шейке образца происходит зарождение внутренней трещины, которая быстро растет и разрушает образец по механизму хрупкого или вязко-хрупкого разрушения. Определив к какому типу разрушения оно относится - межкристаллитному, межзеренному или смешанному - можно качественно оценить склонность материала к хрупкому разрушению.

В данном случае анализируя разрушение в шейке, можно оценить хрупкость контролируемого материала при одноосном растяжении, а также вклад ультразвукового упрочнения поверхности на изменение механических свойств металла.

Результаты испытаний образцов, вырезанных из лопасти рабочих колес циркуляционных насосов, представлены в табл. 1.

Таким образом, в результате упрочняющей обработки методом УУО значение предела текучести металла лопасти рабочего колеса циркуляционного насоса увеличилось на 58 \%, предела прочности на $15 \%$. На рис. 7 показана зона разрыва образцов на растяжение в исходном состоянии, на рис. 8 после ультразвуковой поверхностной обработки.

Утяжка в шейке образца (см. рис. 7) происходит как вязкое разрушение с небольшой площадью хрупкого разрушения, а после ультразвуковой обработки - как хрупко-вязкое разрушение (см. рис. 8) аналогично типичному вязко-хрупкому разруше-

Таблица 1. Результаты испытаний образцов, вырезанных из лопасти рабочих колес циркуляционных насосов

[Table 1. Trial results for samples, cut from impeller vane of circulating pump]

\begin{tabular}{|l|c|c|}
\hline \multirow{2}{*}{\multicolumn{1}{|c|}{ Index }} & \multicolumn{2}{|c|}{ Sample condition } \\
\cline { 2 - 3 } & $\begin{array}{c}\text { Before an ultrasonic impact } \\
\text { treatment }\end{array}$ & $\begin{array}{c}\text { After an ultrasonic impact } \\
\text { treatment }\end{array}$ \\
\hline Elasticity modulus $E, \mathrm{GPa}$ & 210 & 210 \\
\hline Yield stress $R_{p 0,2}, \mathrm{MPa}$ & 175 & 276 \\
\hline Stress limit $R_{m}, \mathrm{MPa}$ & 396 & 455 \\
\hline Ratio $R_{p 0,2} / R_{m}, \%$ & 44.19 & 60.65 \\
\hline Contraction ratio $Z, \%$ & 63 & 42 \\
\hline
\end{tabular}




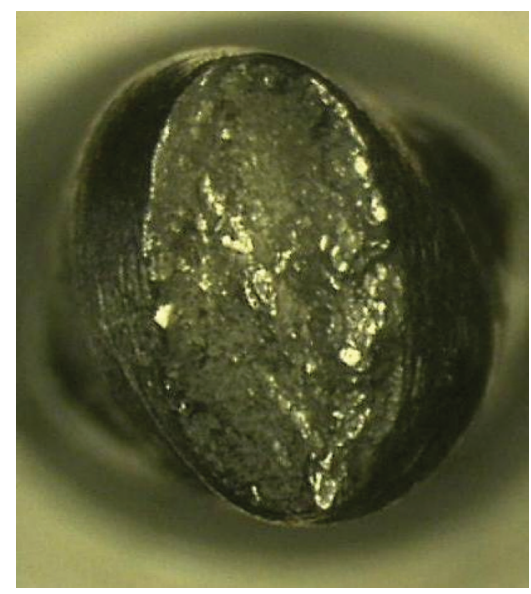

Рис. 7. Вид зоны разрыва образца на одноосное растяжение в исходном состоянии

[Fig. 7. Uniaxial tension fracture zone view, initial]

нию стали («чашечка-конус»). Стадия текучести в последнем случае наступила на поверхности упрочненного образца гораздо позже, чем на образце без предварительной обработки.

Полученные результаты подтверждают эффективность поверхностной ударной ультразвуковой обработки. В целях восстановления служебных свойств металла лопастей рабочих колес циркуляционных насосов энергоблока № 1 Нововоронежской АЭС-2 была разработана следующая последовательность (технология) их ремонта:

- выполнение визуального и измерительного контроля (ВиИК), капиллярного контроля (КК), радиографического контроля (РГК) лопастей в объеме $100 \%$ и определение участков с недопустимыми дефектами;

- механическая выборка (удаление/вырезка) недопустимых дефектов и последующая заварка образованных выборок с восстановлением геометрических характеристик лопастей рабочих колес циркуляционных насосов без проведения последующей термообработки для снятия напряжений;

- проведение ударной ультразвуковой обработки поверхности лопастей в объеме $100 \%$.

Для выполнения работ по ударной ультразвуковой обработки поверхности лопастей циркуляционных насосов после исправления дефектов и доработки (наплавки) основного металла (отдельные технологические карты) была разработана «Технологическая карта поверхностного упрочнения».

В период с 13.02.2016 г. по 10.03.2016 г. на энергоблоке № 1 Нововоронежской АЭС-2 в соответс-

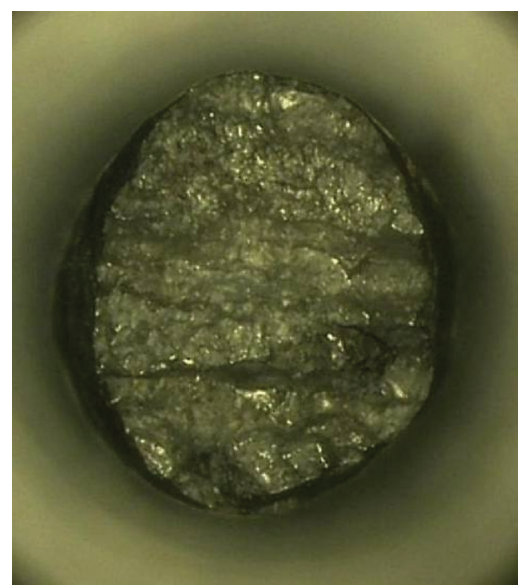

Рис. 8. Вид зоны разрыва образца на одноосное растяжение после УЗ обработки

[Fig. 8. Uniaxial tension fracture zone view, after UIT]

твии с этой технологической картой были проведены работы по поверхностному упрочнению металла 32 лопастей рабочих колес циркуляционных насосов.

\section{ВЫВОДЫ}

1. Ультразвуковая ударная обработка поверхности, в том числе при наличии неглубоких поверхностных дефектов, обладает следующими достоинствами:

- уменьшает структурные поверхностные неоднородности материала;

- существенно упрочняет поверхностный слой;

- перераспределяет благоприятным образом поле остаточных напряжений и создает на поверхности металла высокие фоновые напряжения сжатия;

- увеличивает прочностные характеристики металла.

Так, при обработке металла с дефектом (с трещиной) отмечено существенное сокращения ширины дефекта не менее чем в 10 раз, на глубину 1 мм.

2. Измеренные значения микротвердости и контрольные испытания образцов показывают, что ультразвуковое упрочнение поверхности металла гарантированно распространяется на глубину 1.5 мм, тем самым приводит к увеличению на $60 \%$ значение предела текучести и на $15 \%$ значения предела прочности.

3. Проведенные исследования доказали эффективность проведения УУО для восстановления металла лопастей колес циркуляционных насосов. 


\section{СПИСОК ЛИТЕРАТУРЫ}

1. ГОСТ 18442-80. Контроль неразрушающчий. Капиллярные методы. Общчие требования.

2. ГОСТ 977-88. Отливки стальнье. Общчие технические условия.

3. ГОСТ 1778-70. Сталь. Металлографические методы определения неметаллических включений.

4. ГОСТ 5639-82. Стали и сплавы. Методы выявления и определения величины зерна.
5. Бабей Ю. И. Физические основы импульсного упрочнения стали и чугуна. Киев: Наук. Думка, 1988, $240 \mathrm{c}$.

6. Муханов И. И. // Вестникмашиностроения, 1968, № 6, c. 64-66.

7. ГОСТ 2999-75. Металль и сплавы. Методы измерения твердости по Виккерсу.

8. ГОСТ 1497-84. Металльл. Методы испытаний на растяжение.

\title{
RESTORATION OF THE PROPERTIES OF CICULATION PUMPS BLADES METALS BY SURFACE ULTRASONIC IMPACT TREATMENT
}

\author{
(C) 2017 V. P. Povarov', O. V. Urazov', M. B. Bakirov' ${ }^{1}$, S. S. Pakhomov ${ }^{2}$ \\ ${ }^{I}$ The branch of JSC «Concern Rosenergoatom» «Novovoronezh Nuclear Power Plant» (Novovoronezh NPP), \\ industrial zone, 1 Yuzhnaya, 396071 Voronezh reg., Novovoronezh, Russia \\ ${ }^{2}$ Center of material science and lifetime management (CMSLM, Ltd), 1 Zhukovskogo str., \\ 140180 Moscow reg., Zhukovskij, Russia \\ e-mail:PovarovVP@nvnpp1.rosenergoatom.ru,UrazovOV@nvnpp1.rosenergoatom.ru
}

Received 10.04.2017

\begin{abstract}
During the transition period to a market economy, factoryies- manufacturers of equipment for the nuclear industry became lame duck companies. The Mmarket of for heavy industry equipment reduced dramatically, quality control requirements imposed to on the goods became lowered. Deviations from regulations requirements, technical specifications for equipment manufacture, resulted in an inevitable decrease of reliability not only during operations stage but also during check teststests. It is not always possible to promptly replace non-conforming equipment, in such cases it is required to apply compensatory measures to restore properties up to an acceptable level in order to ensure operational reliability due to the strength improvement of equipment parts and structures during the whole service life or up to the scheduled date of equipment replacement.

This paper is dedicated to the development and practical implementation of surface ultrasonic treatment restoration technology used for working with the metal wheels blades metal of circulation pumps of type 16DPA10-28 located at Novovoronezh NPP-2 unit pump station 10URS. Dynamic surface treatment was implemented to compensate for the process flaws of the metal blades metal. It was demonstrated that impact elastic-plastic deformation has a comprehensive compensation impact on the metal blades metal of the equipment's initial state and creates a surface hardening layer of $1, .5 \mathrm{~mm}$ with higher strength properties. Surface strain hardening increases the cyclic strength, re-distributes the beneficially residual process and maintenance stress, as well as heals repairing minor surface cracks improving the surface quality. The developed technology was used for the treatment of 32 blades of circulation pumps 10PAC01AP001, 10PAC02AP001, 10PAC03AP001, 10PAC04AP001 working wheels. 100-hours tests in situ proved the high efficiency of the developed technology and allow us to recommend its application at during the stage of blades manufacture of the blades as well as during the operational lifetime of the pumps operation with the a view to extending their service life.
\end{abstract}

Keywords: plastic strain, surface defect, residual welding stress, ultrasonic impact treatment, circulation pump.

\section{REFERENCES}

1. GOST 18442-80. Non-destructive Testing. Dye Penetrant Methods. General Requirements.

2. GOST 977-88. Steel Castings. General Technical Specifications.
3. GOST 1778-70. Steel. Metallographic Methods to Determine a Non-metallic Inclusions.

4. GOST 5639-82. Steels and Alloys. Methods to Identify and Determine the Amount of Grain. 
5. Babey Yu. I. Physical Bases of Pulse Hardening of Steel and Iron. Kiev: Nauk. Dumka Publ., 1988, 240 p. (in Russia)

6. Mukhanov I. I. Bulletin of Engineering, 1968, no. 6, pp. 64-66. (in Russia)
7. GOST 2999-75. Metals and Alloys. Vickers Hardness Testing Methods.

8. GOST 1497-84. Metals. Tensile Testing Methods.
Поваров Владимир Петрович - к. т. н., директор Нововоронежской АЭС; e-mail: PovarovVP@nvnpp1. rosenergoatom.ru

Уразов Олег Владимирович - начальник отдела дефектоскопии металлов и технического контроля Нововоронежской АЭС; e-mail: UrazovOV@nvnpp1. rosenergoatom.ru

Бакиров Мурат Баязитович - д. т. н., генеральный директор ООО «НСУЦ «ЦМиР»; e-mail: mareeva-test@ yandex.ru

Пахомов Сергей Сергеевич - и. о. начальника лаборатории ООО «НСУЦ «ЦМиР»; e-mail: sergeypakhomov87@ gmail.com
Povarov Vladimir P. - Cand. Sci. (Eng.), Director of the Novonoronezh NPP; e-mail: PovarovVP@nvnpp1. rosenergoatom.ru

Urazov Oleg V. - Head of Department of Metals Defectoscopy and Technical Control of the Novonoronezh NPP; e-mail: UrazovOV@nvnpp1.rosenergoatom.ru

Bakirov Murat B. - Dr. Sci. (Eng.), Director-general of CMSLM Ltd.; e-mail: mareeva-test@yandex.ru

Pakhomov Sergey S. - Acting Head of the Laboratory of CMSLM Ltd.; e-mail: sergeypakhomov87@gmail.com 